\title{
PENGARUH KOMUNIKASI TERHADAP KINERJA PEGAWAI PADA BAGIAN ASPIRASI HUMAS DAN PROTOKOL SEKRETARIAT DPRD PROVINSI LAMPUNG
}

\author{
Tiar Mirnasari ${ }^{(1)^{*}}$, Nia Septiana Sari ${ }^{(2)}$ \\ Fakultas Ekonomi Universitas Sang Bumi Ruwa Jurai \\ tiar_mirnasari@yahoo.com,niaseptianasari@gmail.com
}

\begin{abstract}
Abstrak. Komunikasi dirasakan sangat penting dalam segala aspek kehidupan. Komunikasi mampu meningkatkan keharmonisan kerja dalam organisasi dan sebaliknya apabila komunikasi tidak efektif maka koordinasi akan terganggu dan mengakibatkan terganggunya proses pencapaian target dan tujuan dinas.Tujuan dari penelitian ini adalah Untuk mengetahui pengaruh komunikasi terhadap kinerja pegawai pada bagian Aspirasi Humas dan Protokol Sekretariat DPRD Provinsi Lampung.Pengumpulan data yang digunakan berupa data primer dan data sekunder. Penelitian ini menggumakan jenis kuantitatif dengan metode analisis regresi linier sederhana.Teknik pengumpulan data yang digunakan adalah observasi, wawancara, dokumentasi dan quisioner/ daftar pertanyaan. Sampel dalam penelitian ini terdiri dari jumlah responden sebanyak 30 orang responden pegawai Bagian Aspirasi Humas dan Protokol Sekretariat DPRD Provinsi Lampung. Berdasarkan analisa kuantitatif diperoleh Nilai F hitung sebesar 51,093, kemudian nilai F tabel 3,95, ini berarti F hitung > F tabel, sehingga dapat disimpulkan bahwa Komunikasi (X) berpengaruh terhadap Kinerja (Y) pada Bagian Aspirasi Humas dan Protokol Sekretariat DPRD Provinsi Lampung. Persamaan regresi adalah sebesar $\mathrm{Y}=0,598+0,825 \mathrm{X}$, yang artinya setiap kenaikan satu point dari variabel Komunikasi akan diikuti oleh variabel Kinerja Pegawai sebesar 0,803 point. Kontribusi (R Square ) sebesar 0.645 artinya sebesar $64,50 \%$ variasi perubahan variabel Komunikasi sedangkan sisanya dijelaskan oleh variabel lain diluar dari variabel penelitian ini.
\end{abstract}

Kata kunci: Komunikasi, Kinerja Pegawai

\section{PENDAHULUAN}

Sumber daya manusia harus dikelola dengan sebaik-baiknya untuk meningkatkan efektivitas dan efisiensi organisasi. Peningkatan sumber daya manusia dalam setiap sendi organisasi, perusahaan atau pun pemerintahan menjadi suatu tuntutan yang tidak bisa ditawar lagi apabila ingin mencapai suatu keberhasilan, mengingat perkembangan pembangunan yang dilaksanakan juga semakin pesat dan penuh tantangan.

Pada berbagai bidang khususnya kehidupan berorganisasi, faktor manusia merupakan masalah utama disetiap kegiatan yang ada di dalamnya. Organisasi merupakan kesatuan sosial yang dikoordinasikan secara sadar dengan sebuah batasan yang reaktif dapat di identifikasikan, bekerja secara terus menerus untuk mencapai tujuan (Robbins, 2008). Semua tindakan yang diambil dalam setiap kegiatan diprakarsai dan ditentukan oleh manusia yang menjadi pegawai perusahaan/organisasi.

Umumnya setiap pemerintahan selalu menggunakan tenaga kerja manusia, meskipun pada proses pekerjaannya dibantu dengan mesin-mesin yang bersifat otomatis seperti komputer, laptop dan alat bantu lainnya. Kualitas tenaga kerja (sumber daya 
manusia) merupakan faktor utama yang mempengaruhi perkembangan dan pertumbuhan ekonomi suatu negara. Kualitas tenaga kerja bukan semata-mata didasarkan pada pandangan yang kualitatif, dalam arti hanya terbatas pada kualitas yang dapat diukur, yang biasanya diwujudkan pada tingkat pendidikan yang ditamatkan atau dimiliki oleh tenaga kerja tersebut. Tetapi lebih luas dari pada itu, kualitas tenaga kerja dilihat dari segi tingkah laku tenaga kerja itu sendiri yang menyangkut kebiasaan kerja, adanya motivasi, keinginan untuk terus meningkatkan diri, berusaha membuat penemuan-penemuan baru, kreatif, komunikatif, bersemangat untuk kerjasama, dan memiliki kinerja yang tinggi. Menurut Anoraga (Anoraga, 2010), ketenangan dan kegairahan kerja dipengaruhi oleh kepribadian pekerja (motivasi, komunikasi dan yang lainnya), komunikasi, kesempatan untuk berkembang, fasilitas kerja dan rekan sekerja yang menyenangkan, kemudian yang terakhir adalah faktor kesejahteraan.

Tingkah laku pegawai di lingkungan kantor harus dibangun melalui komunikasi yang sehat. Komunikasi diperlukan untuk memelihara hubungan antar pegawai atau hubungan antara pegawai dengan pimpinan. Menurut Effendy (2013: 60), komunikasi adalah proses penyampaian suatu pesan dalam bentuk lambang bermakna sebagai pikiran dan perasaan berupa ide, informasi, kepercayaan, harapan, himbauan, dan sebagai panduan yang dilakukan oleh seseorang kepada orang lain, baik langsung secara tatap muka maupun tidak langsung melalui media, dengan tujuan mengubah sikap, pandangan atau prilaku. Melalui komunikasi berbagai hal yang menyangkut kehidupan organisasi dapat disampaikan oleh satu pihak kepada pihak yang lain. Meskipun suatu organisasi telah menggunakan alat-alat komunikasi yang mutakhir dan memiliki pimpinan yang pandai berbicara yang dapat menyampaikan dengan cepat seluruh instruksi- instruksi, petunjuk, saran dan sebagainya, akan tetapi hal ini belum menjamin bahwa komunikasi telah dilakukan dengan baik (Nitisemito, 2011: 239). Hal ini memberikan pengertian bahwa meskipun suatu organisasi telah menggunakan alat-alat komunikasi yang modern dan memiliki pimpinan yang pandai berbicara masih memungkinkan terjadinya miss communication dan miss understanding.

Bagian Aspirasi Humas dan Protokol Sekretariat DPRD Provinsi Lampung mempunyai tugas membantu dan bertanggungjawab kepada Kepala Bagian Umum, yang mempunyai tugas pokok melaksanakan penyiapan bahan dan petunjuk teknis kegiatan hubungan masyarakat dan keprotokolan yang berhubungan dengan kegiatan DPRD. Dalam melaksanakan perannya tersebut, pegawai yang memiliki kemampuan dan keahlian dibidangnya menjadi variabel utama dalam melaksanakan tugas dan fungsi Bagian Aspirasi Humas dan Protokol Sekretariat DPRD Lampung. Berkaitan dengan kedudukan, tugas dan fungsi Bagian Aspirasi Humas dan Protokol Sekretariat DPRD Provinsi Lampung berusaha meningkatkan kinerja dalam hal pelayanan. Secara umum, pelayanan yang ada selama ini dirasa belum optimal.

Komunikasi dirasakan sangat penting dalam segala aspek kehidupan. Komunikasi mampu meningkatkan keharmonisan kerja dalam organisasi dan sebaliknya apabila komunikasi tidak efektif maka koordinasi akan terganggu dan mengakibatkan terganggunya proses pencapaian target dan tujuan dinas. Berdasarkan pengamatan peneliti di Bagian Aspirasi Humas dan Protokol Sekretariat DPRD Provinsi Lampung, dapat diketahui bahwa kinerja pegawai di kantor tersebut belum maksimal. 
Kinerja pegawai adalah hasil kerja pegawai secara keseluruhan atau selama periode tertentu baik secara kualitas maupun kuantitas berdasarkan kriteria yang telah ditentukan dan disepakati terlebih dahulu.(Sari \& Hadijah, 2016).

Kinerja pegawai Bagian Aspirasi Humas dan Protokol Sekretariat DPRD Lampung belum maksimal. Penyelenggaraan administrasi yang kurang baik terlihat dari sering terjadinya kehilangan surat dinas yang penting sebagai arsip, dimana dalam sebulan Bagian Aspirasi Humas dan Protokol Sekretariat DPRD Lampung dapat mengalami kehilangan surat dua hingga tiga kali. Kejadian ini memperlihatkan bahwa rendahnya tingkat pengarsipan surat penting. Selanjutnya, seringnya pegawai melaksanakan tugas sesuai dengan persepsinya sendiri juga memperlihatkan bahwa kurangnya komunikasi antara pimpinan dan pegawai. Hal ini terlihat dari rendahnya jumlah pelaksanaan rapat-rapat koordinasi antar pegawai dan pimpinan sehingga sering terjadinya kesalahan dari tugas yang dikerjakan. Kinerja yang belum maksimal seperti tersebut diatas memperlihatkan kurangnya komunikasi antar pegawai untuk mendapatkan hasil kerja yang terbaik. Dengan adanya efektivitas komunikasi organisasi diharapkan mampu memberikan pengaruh terhadap kinerja pegawai. Adanya komunikasi yang sehat dan baik antar pegawai diharapkan akan turut membantu perkembangan kinerja pegawai. Dengan adanya keterbukaan dan pengertian maka para pegawai akan merasa lebih akrab dapat dijadikan sebagai teman diskusi. Setiap individu dalam bekerja tidak hanya menginginkan sekedar gaji dan prestasi, tetapi bekerja juga merupakan pemenuhan kebutuhan akan interaksi sosial. Pegawai yang memiliki rekan kerja yang ramah dan mendukung, akan mengantarkan para pegawai pada hasil kerja yang baik pula.

Menurut Fajar Komunikasi adalah melalui pemikiran seseoramh yang dapat mempengaruhi pikiran orang kaun dan perubahan sosial.(Fajar, 2013). Kemudian Komunikasi merupakan pemindahan informasi dan pemahaman dari seseorang kepada seseorang. Untuk pemindahkan infor-masi yang dimaksud dalam komunikasi terse-but diperlukan suatu proses komunikasi. Menurut Webster New Collogiate Dictionary "istilah komunikasi berasal dari istilah Latin Communicare, bentuk past participle dari communication dan communicatus yang artinya suatu alat untuk berkomunikasi terutama suatu slstem penyampaian dan penerimaan berita, sepeti mlsalnya telepon, telegrap, radlo, dan lain sebagainya".(Ardiansyah, 2016)

Komunikasi dapat mempengaruhi perilaku karyawan mengenai peristiwa komunikasi, respon karyawan terhadap karyawan lainnya, harapan- harapan, konflik dan kesempatan bagi pertumbuhan dalam organisasi. Untuk itu pihak manajemen harus dapat menciptakan dan memelihara suatu kondisi komunikasi dalam perusahaan yang baik dan harmonis.

Pihak pimpinan harus dapat lebih memahami karyawannya melalui berbagai pendekatan. Salah satu pendekatan yang paling penting adalah dengan berkomunikasi dan berinteraksi dengan mereka secara interpersonal sehingga karyawan merasa diperhatikan dan merasa diakui. Keharmonisan dalam berkomunikasi ini harus selalu dijaga karena dapat mempengaruhi sikap mental karyawan. Ketidakharmonisan dalam komunikasi dapat menimbulkan terjadinya hubungan kerja yang kurang baik, dan apabila hal ini dibiarkan, maka akan menimbulkan implikasi yang kurang baik terhadap gairah kerjadan pada akhirnya akan membawa 
dampak negatif terhadap kinerjanya. Masalah komunikasi interpersonal ini tentunya harus mendapatkan perhatian lebih, karena bisa berdampak pada kegiatan operasional organisasi. Seorang pemberi pesan/ informasi (komunikator), harus dapat mengkomunikasikan informasi yang dibawanya kepada penerima pesan (receiver) dengan baik dan dapat dipahami maksudnya, sehingga tidak akan terjadi perbedaan persepsi diantara para penerima pesan. Dengan demikian semua kegiatan operasional organisasi akan berjalan dengan lancar.

Berdasarkan penelitian sebelumnya oleh Damayanti dkk. yang berjudul pengaruh kepuasan kerja terhadap kinerja karyawan (studi kasus karyawan non medis rs islam siti khadijah palembang) komunikasi mempunyai pengaruh terhadap kinerja pegawai pada bagian aspirasi humas dan protokol sekretariat dprd provinsi lampung.(Damayanti et al., 2018). Penelitian selanjutnya oleh Kurniawan dkk bahwasannya perusahaan dapat meningkatkan kesadaran karyawan dalam mematuhi peraturan yang ada meskipun tidak ada pengawasan, memberikan insentif, memahami tugas dan promosi sehingga dapat mendorong karyawan untuk bekerja.(Kurniawan \& Mardiana, 2019). Kemudian Hasil menunjukkan bahwa komunikasi berpengaruh secara simultan terhadap kinerja pegawai negeri sipil dan berpengaruh secara parsial. Diharapkan para pegawai dinas kesehatan kota malang tetap melakukan komunikasi dengan baik secara konsisten.(Fajar, 2013)

Alasan penulis lebih memfokuskan penelitian pada komunikasi adalah karena permasalahan yang peneliti rasa masih kurang di Bagian Aspirasi Humas dan
Protokol Sekretariat DPRD Lampung yaitu mengenai komunikasi antar pegawai yang mengakibatkan kinerja tidak baik. Komunikasi merupakan sarana untuk mengadakan koordinasi antara berbagai subsistem dalam sebuah perusahaan. Kompetensi komunikasi yang baik antar karyawan akan mampu memperoleh dan mengembangkan tugas yang diembannya, sehingga tingkat kinerja suatu organisasi menjadi semakin baik dan sebaliknya.

Berdasarkan uraian di atas, penulis tertarik menelitinya lebih lanjut menjadi sebuah judul skripsi yaitu "Pengaruh Komunikasi Terhadap Kinerja Pegawai pada Bagian Aspirasi Humas dan Protokol Sekretariat DPRD Provinsi Lampung".

\section{METODE PENELITIAN}

Jenis penelitian menggunakan kuantitatif dengan menggunakan metode analisis regresi sederhana. Tujuan dari penelitian ini adalah

Sumber data yang digumakan adalah data primer dan data skunder. Teknik pengumpulan menggunakan observasi, wawancara, dokumentasi dan kuesioner.

\section{Analisis Kualitatif}

Analisis kualitatif dilakukan dengan analisis tabel tunggal atau secara parsial yang menggambarkan kriteria masingmasing variabel independent, dalam penelitian ini yaitu variabel Komunikasi (X) dan variabel dependent yaitu Kinerja Pegawai (Y). Termasuk kedalam kriteria mana masing-masing variabel penelitian tersebut sesuai dengan jawaban yang ada pada pengukuran variabel diatas.

Kriteria masing-masing variabel pada analisis tabel mengacu pada interval skor dengan rumus sebagai berikut : 
$\mathrm{I}=\mathrm{NT}-\mathrm{NR} / \mathrm{JI}$

Keterangan :

I = Lebar interval

NT = Nilai tertinggi

$\mathrm{NR}=$ Nilai terendah

JI = Jumlah interval

(Sudjana, 2009:28)

\section{Analisis regresi linear sederhana}

Adapun persamaan regresi linier sederhananya adalah sebagai berikut :

$$
\mathbf{Y}=\mathbf{a}+\mathbf{b} \mathbf{X}
$$

\section{Keterangan :}

$\mathrm{Y}=$ Kinerja Pegawai

$\mathrm{A}=$ Intercept (harga Konstan)

$\mathrm{b}=$ Koefisien Regresi

$\mathrm{X}=$ Komunikasi

(Sugiyono, 2019)

\section{Koefisien Determinasi}

Untuk melihat seberapa besar tingkat pengaruh variabel independen terhadap variabel dependen secara parsial digunakan koefisien determinasi. Untuk mengetahui seberapa besar kontribusi dari Kepuasan Kerja sebagai variabel independen terhadap Kinerja Pegawai sebagai variabel dependen, dilakukan perhitungan statistik dengan menggunakan koefisien determinasi (Kd). Rumus dari koefisien determinasi sebagai berikut:

$$
K_{d}=R^{2} \times 100 \%
$$

\section{Keterangan}

$\mathrm{KD}=$ Koefisien determinasi

$\mathrm{R}=$ Koefisien Korelasi

( Sugiyono, $2014: 271$ )

\section{HASIL DAN PEMBAHASAN}

\section{Analisis Kuantitatif}

\section{a. Uji F}

Berdasarkan hasil pengujian mengguanakan Software SPSS Versi 21, maka diperoleh Hasil Uji F Komunikasi (X) dengan Variabel Kinerja Pegawai (Y) adalah Dari uji anova atau $\mathrm{F}$ test didapat $\mathrm{F}$ hitung sebesar 51,093 dengan tingkat signifikan 0,000 karena probability jauh lebih kecil dari 0,05 , kemudian nilai $\mathrm{F}$ tabel 3,95, ini berarti $\mathrm{F}$ hitung $>\mathrm{F}$ tabel, sehingga dapat disimpulkan bahwa; Hipotesis yang menyatakan terdapat pengaruh antara Variabel Komunikasi (X) dengan Kinerja Pegawai (Y) pada Bagian Aspirasi Humas dan Protokol Sekretariat DPRD Provinsi Lampung dapat diterima. Jadi variabel Komunikasi (X) berpengaruh dengan Kinerja Pegawai (Y) pada Bagian Aspirasi Humas dan Protokol Sekretariat DPRD Provinsi Lampung.

\section{Analisis Regresi Linier antara Komunikasi (X) Terhadap Kinerja Pegawai (Y)}

Berdasarkan hasil penelitian, maka diperoleh data Pengaruh Komunikasi (X) dengan Kinerja Pegawai (Y) sebagai berikut

\section{Coefficients $^{a}$}




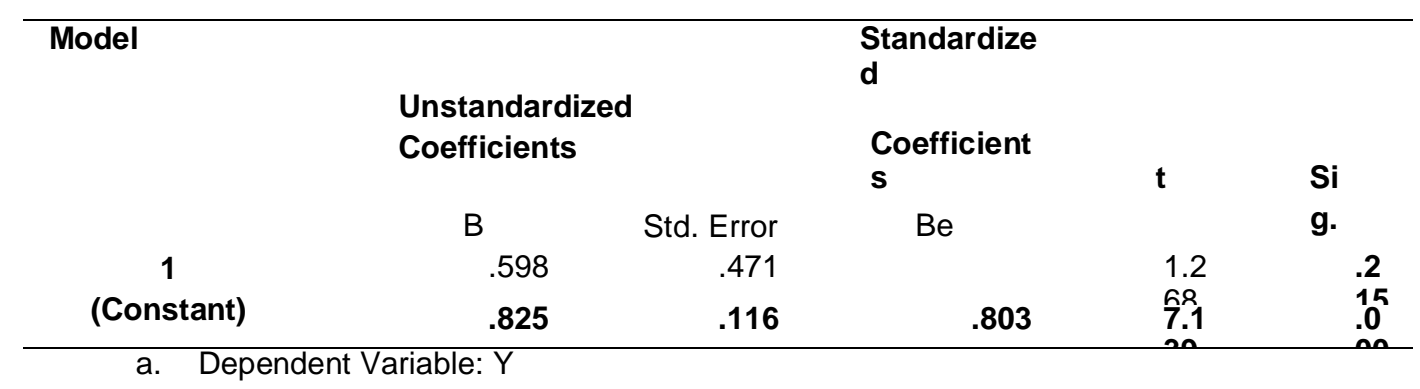

Persamaan regresi antara variabel Komunikasi (X) terhadap Kinerja Pegawai (Y) adalah $\mathrm{Y}=0,598+0,825 \mathrm{X}$, yang artinya setiap kenaikan satu point dari variabel Komunikasi akan diikuti oleh variabel Kinerja Pegawai sebesar

0,825 poin.

\section{Koefisien Determinasi}

Berdasarkan hasil penelitian di atas, maka diperoleh Koefisien Determinasi

Komunikasi (X) dengan Variabel Kinerja Pegawai (Y) adalah sebagai berikut:

\begin{tabular}{|c|c|c|c|c|}
\hline \multicolumn{5}{|c|}{ Model Summary } \\
\hline $\begin{array}{l}\text { Mode } \\
\text { I }\end{array}$ & & & $\begin{array}{c}\text { Adjuste } \\
\text { d R }\end{array}$ & $\begin{array}{l}\text { Std. Error of } \\
\text { the }\end{array}$ \\
\hline 1 & .80 & .6 & .633 & .343 \\
\hline
\end{tabular}

a. Predictors: (Constant), $X$

b. Dependent Variable: $Y$

Koefisien Determinasi $(\mathrm{KD})=\mathrm{R} 2=$ dalam organisasi dan sebaliknya apabila $0,8032=0,645=0,645 \times 100 \%=64,50 \%$.

Dapat disimpulkan bahwa variabel Komunikasi (X) menjelaskan variasi perubahan variabel Kinerja Pegawai (Y) sebesar $64,50 \%$, sedangkan sisanya dijelaskan oleh faktor lain yang tidak dikaji dalam penelitian ini.

\section{Pembahasan}

Dari hasil penelitian dinyatakan bahwa Komunikasi (X) pada Pegawai Bagian Aspirasi Humas dan Protokol Sekretariat DPRD Provinsi Lampung dalam kategori baik Hal ini menunjukkan bahwa Komunikasi memberikan kontribusi dalam meningkatkan Kinerja Pegawai (Y).

Komunikasi dirasakan sangat penting dalam segala aspek kehidupan. Komunikasi mampu meningkatkan keharmonisan kerja komunikasi tidak efektif maka koordinasi akan terganggu dan mengakibatkan terganggunya proses pencapaian target dan tujuan dinas. Effendy (2013: 60), mendefinisikan komunikasi adalah proses penyampaian suatu pesan dalam bentuk lambang bermakna sebagai pikiran dan perasaan berupa ide, informasi, kepercayaan, harapan, himbauan, dan sebagai panduan yang dilakukan oleh seseorang kepada orang lain, baik langsung secara tatap muka maupun tidak langsung melalui media, dengan tujuan mengubah sikap, pandangan atau prilaku. Melalui komunikasi yang efektif, diharapkan kinerja pegawai organisasi akan semakin baik pula, karena setiap individu dalam bekerja tidak hanya menginginkan sekedar gaji dan prestasi tetapi bekerja juga merupakan pemenuhan kebutuhan akan interaksi sosial. Komunikasi yang efektif, 
dapat membuat suatu organisasi semakin kokoh dan kinerja pegawai akan meningkat.

Berdasarkan hasil penelitian diketahui bahwa variabel Komunikasi (X) mempunyai pengaruh yang positif terhadap variabel Kinerja Pegawai (Y). Hasil penelitian ini juga sesuai dengan penelitian terdahulu yaitu penelitian dari Putu Anggreyani Widya Astuti yang berjudul Pengaruh Komunikasi Terhadap Kinerja Pegawai Pada Badan Kepegawaian Kabupaten Tambrauw (2016), yang menyatakan bahwa secara simultan variabel bebas Komunikasi (X) berpengaruh signifikan terhadap variabel terikat yaitu kinerja karyawan (Y). Demikian juga dengan penelitian Didi Wandi,Suhroji Adha dan Iyah Asriyah yang berjudul Pengaruh Komunikasi Terhadap Kinerja Pegawai Pada Badan Penanggulangan Bencana Daerah (BPBD) Provinsi Banten (2019), yang menyatakan bahwa Komunikasi yang terdapat pada instansi dapat memberikan pengaruh terhadap kinerja pegawai. Serta penelitian dari Dimas Okta Ardiansyah Pengaruh Komunikasi Terhadap Kinerja Karyawan (Studi Pada Bagian Produksi Pabrik Kertas PT. Setia Kawan Makmur Sejahtera Tulungagung) (2016), yang menyatakan bahwa Komunikasi mempunyai pengaruh terciptanya kinerja.

\section{KESIMPULAN}

Berdasarkan analisis dan pembahasan maka dapat diambil kesimpulan bahwa, Komunikasi mempunyai pengaruh terhadap kinerja pegawai pada Bagian Aspirasi Humas dan Protokol Sekretariat DPRD Provinsi Lampung.

\section{Saran-Saran}

Berdasarkan hasil penelitian,
pembahasan, dan kesimpulan yang diperoleh, maka saran yang dapat diberikan adalah :

1. Untuk meningkatkan Komunikasi pegawai Bagian Aspirasi Humas dan Protokol Sekretariat DPRD Provinsi Lampung agar mencapai kinerja yang optimal perlu dilakukan, diantaranya dengan cara meningkatkan komunikasi antar pegawai dalam pelaksanaan program-program yang sesuai dengan pekerjaan pegawai.

2. Penelitian selanjutnya sebaiknya mempertimbangkan objek yang lebih luas. Hal ini bertujuan agar kesimpulan yang dihasilkan nanti memiliki cakupan yang lebih luas juga

\section{DAFTAR PUSTAKA}

Anoraga, P. (2010). Manajemen Bisnis, Edisi Kedua. Rineka Cipta.

Ardiansyah, D. O. (2016). PENGARUH KOMUNIKASI TERHADAP KINERJA KARYAWAN DENGAN DIMEDIASI OLEH KEPUASAN KERJA. 3, 15.

Damayanti, R., Hanafi, A., \& Cahyadi, A. (2018). PENGARUH KEPUASAN KERJA TERHADAP KINERJA KARYAWAN (STUDI KASUS KARYAWAN NON MEDIS RS ISLAM SITI KHADIJAH PALEMBANG). JEMBATAN, 15(2), 75-86. https://doi.org/10.29259/jmbt.v15i2. 6655 
Fajar. (2013). Komunikasi Politik Teori, Aplikasi dan Strategi di Indonesia. Mata Padi Pressindo.

Kurniawan, F., \& Mardiana, N. (2019). PENGARUH BUDAYA KERJA DAN MOTIVASI KERJA TERHADAP KINERJA KARYAWAN DENGAN KEPUASAN KERJA SEBAGAI VARIABEL INTERVENING. 5(03), 15.

Sari, R. N. I., \& Hadijah, H. S. (2016). PENINGKATAN

KINERJA

\begin{tabular}{lrr} 
PEGAWAI & \multicolumn{2}{r}{ MELALUI } \\
KEPUASAN & KERJA & DAN \\
DISIPLIN & KERJA. & Jurnal \\
Pendidikan & \multicolumn{2}{c}{ Manajemen } \\
Perkantoran, & 1(1), & 204. \\
https://doi.org/10.17509/jpm.v1i1.3 & \\
389 &
\end{tabular}

Sugiyono. (2019). Penelitian Kuantitatif Kualitatif dan $R \& D$. Alfabeta. 